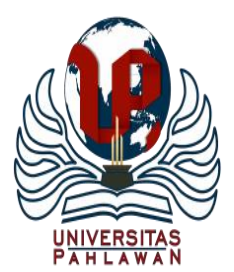

\title{
JURNALBASICEDU
}

Volume 5 Nomor 5 Tahun 2021 Halaman 3150 - 3157

Research \&Learningin Elementary Education

https://jbasic.org/index.php/basicedu

\section{Meta Analisis Model Pembelajaran Cooperative Learning Tipe Student Team Achievement Divisions terhadap Hasil Belajar Kognitif Siswa Sekolah Dasar}

\author{
Kezia Febri Kristiani ${ }^{1 凶}$, Gamaliel Septian Airlanda ${ }^{2}$ \\ Pendidikan Guru Sekolah Dasar, Universitas Kristen Satya Wacana Salatiga, Indonesia ${ }^{1,2}$ \\ E-mail:292017168@ student.uksw.eduu', gama.airlanda@ @staff.uksw.eduu ${ }^{2}$
}

\begin{abstract}
Abstrak
Tujuan dari penelitian ini adalah untuk mengetahui apakah model pembelajaran model Cooperative Learning tipe STAD (Student Team Achievement Divisions) dapat diterapkan terhadap siswa dalam meningkatkan hasil belajar kognitif siswa dan mengetahui pengaruh model pembelajaran tersebut terhadap hasil belajar kemampuan kognitif siswa. Pada penelitian ini menggunakan metode Meta Analisis. Dengan pedoman data secara kuantitatif. penelitian ini menggunakan perhitungan dengan teknik analisis besaran pengaruh (effect size). Sampel yang diambil adalah 21 artikel publikasi ilmiah tentang pembelajaran Cooperative Learning terhadap hasil belajar kognitif siswa sekolah dasar. Sedangkan hasil penelitian dari penelitian ini adalah bahwa model pembelajaran Cooperative Learning Tipe STAD (Student Team Achievement Divisions) berpengaruh sangat besar dalam meningkatkan hasil belajar siswa kognitif siswa sekolah dasar. Hal ini dapat dilihat bahwa model pembelajaran Cooperative Learning Tipe STAD dapat meningkatkan hasil belajar kognitif di sekolah dasar. Terdapat peningkatan hasil belajar dengan rata-rata sebesar 34,52\% mulai dari peningkatan terendah 7,13\% sampai yang tertinggi 42,80\%. sehingga bisa dikatakan dengan menggunakan model pembelajaran Cooperative Learning tipe STAD (Student Team Schievement Divisions) berpengaruh sangat besar dalam meningkatkan hasil belajar kognitif siswa sekolah dasar.
\end{abstract}

Kata Kunci: : Cooperative Learning tipe STAD (Student Team Achievement Divisions), hasil belajar kognitif, sekolah dasar.

\begin{abstract}
The purpose of this study was to determine whether the cooperative learning model type STAD (Student Team Achievement Divisions) could be applied to students in improving students' cognitive learning outcomes and to determine the effect of the learning model on students' cognitive abilities learning outcomes. In this study using the Meta Analysis method. With quantitative data guidelines. This study uses calculations with the analysis technique of the magnitude of the effect (effect size). The samples taken were 21 scientific publication articles about cooperative learning on cognitive learning outcomes of elementary school students. Meanwhile, the results of this study are that the STAD (Student Team Achievement Divisions) Cooperative Learning learning model has a very large effect in improving cognitive student learning outcomes for elementary school students. It can be seen that the STAD Type Cooperative Learning learning model can improve cognitive learning outcomes in elementary schools. There is an increase in learning outcomes with an average of $34.52 \%$ starting from the lowest increase of $7.13 \%$ to the highest $42.80 \%$. so that it can be said that using the STAD (Student Team Schievement Divisions) Cooperative Learning learning model has a very large effect in improving the cognitive learning outcomes of elementary school students.
\end{abstract}

Keyword: Meta Analysis, STAD Type Cooperative Learning Model, Student Learning Outcomes.

Copyright (c) 2021 Kezia Febri Kristiani, Gamaliel Septian Airlanda

$\triangle$ Corresponding author :

Email : 292017168@student.uksw.eduu

DOI : https://doi.org/10.31004/basicedu.v5i5.1328

ISSN 2580-3735 (Media Cetak)

ISSN 2580-1147 (Media Online) 
3151 Meta Analisis Model Pembelajaran Cooperative Learning Tipe Student Team Achievement Divisions terhadap Hasil Belajar Kognitif SiswaSekolah Dasar - Kezia Febri Kristiani, Gamaliel Septian Airlanda

DOI: https://doi.org/10.31004/basicedu.v5i5.1328

\section{PENDAHULUAN}

Pendidikan merupakan hal penting yang dapat membantu seseorang mendapatkan ilmu dan pengetahuan yang luas serta pemahaman konsep tentang kehidupan. Pendidikan penting ditanamkan sejak dini untuk menjadi bekal anak di masa yang akan datang. Bekal pengetahuan dan ilmu bisa didapatkan sejak berada di bangku sekolah dasar, anak diajarkan untuk mendapatkan ilmu dan pengetahuan yang mengarah ke ranah kognitif, afektif, dan psikomotorik yang dapat membantu anak mendapatkan hasil belajar yang baik. Pengembangan pendidikan terutama dijenjang sekolah dasar seringkali mendapatkan kendala salah satunya ialah masalah ketika proses pembelajaran berlangsung. Untuk menghadapi hal ini diperlukan peran guru itu sendiri sebagai tenaga pendidikan yang secara langsung berinteraksi dengan siswa. Maka dari itu diperlukan guru yang kreatif dalam merencanakan proses pembelajaran agar dapat berjalan secara efisien sehingga dapat mencapai tujuan pembelajaran dengan baik. Prawati (2016) menyatakan bahwa pendidikan yang berjalan secara efektif dan mampu membuat siswa mendapat proses belajar yang bermakna adalah suatu proses pembelajaran yang berkualitas.

Perlu diketahui, saat ini guru dituntut tidak hanya memiliki pengetahuan yang luas, tetapi juga memiliki keterampilan yang baik untuk membuat pembelajaran semakin kreatif, aktif dan inovatif, dan berkualitas karena hal tersebut akan mempengaruhi hasil belajar siswa. Prihatnani \& Supriyadi (2021) juga menyatakan bahwa guru memiliki peran dalam mengoptimalkan hasil belajar siswa. Model pembelajaran merupakan salah satu cara untuk membuat proses belajar mengajar menjadi aktif dan kreatif. Menurut Pendidikan (2016) menyatakan bahwa proses pembelajaran dapat memberikan ruang bagi siswa untuk mengasah kreativitas, bakat dan minat siswa agar dapat berperan secara aktif dalam proses pembelajaran yang diselenggarakan secara, inspiratif, interaktif, menyenangkan, menantang, dan juga memotivasi peserta didik. Saat ini model pembelajaran berpengaruh terhadap hasil belajar siswa,bahwa Model pembelajaran itu sendiri merupakan kerangka atau konsep yang dirancang oleh guru atau tenaga pendidik untuk melaksanakan sebuah proses pembelajaran dengan berbagai cara yang dianggap dapat membuat proses belajar mengajar menjadi lebih efektif sehingga dapat mencapai tujuan pembelajaran. Sejalan dengan pemikiran Munandar (2017)yang menyatakan bahwa "Model pembelajaran dapat digunakan untuk menentukan materi atau konten pembelajaran dan metode-metode untuk penyampaian materi tersebut, dalam arti bahwa model memberikan kerangka untuk menentukan pilihan yang tepat agar pembelajaran dapat berjalan dengan baik". Penelitian ini dilakukan karena saat ini tidak jarang model pembelajaran mengutamakan media yang menarik agar anak menjadi tertarik dan fokus untuk mengikuti pelajaran, tetapi kurang memperhatikan hasil belajar kognitif pada siswa.

Belajar merupakan hasil akhir atau hasil yang didapat setelah belajar hal baru. Sejalan dengan Ayuwanti (2017) yang menyatakan bahwa setelah melalui proses belajar diharapkan siswa mendapatkan hasil akhir yang dapat dipelajari dan menambah pengetahuan. Hal ini sesuai dengan pendapat Nasution (2017) yang menyatakan bahwa hasil belajar dapat berupa metode belajar, tujuan dan hal lain yang dapat dipraktekkan. Hasil belajar mencakup kemampuan kognitif, afektif, dan psikomotorik. Saat ini hasil belajar siswa dijadikan tolak ukur oleh guru untuk memberikan penilaian kepada siswa. Hal ini tentunya berkaitan dengan model pembelajaran yang dipakai dalam proses belajar mengajar saat penyampaian materi berlangsung. Diharapkan dengan model pembelajaran yang aktif dan kreatif membuat peserta didik mampu mengkonstruksi pengetahuan baru dalam upaya meningkatkan penguasaan lebih baik terhadap materi pelajaran. Model pembelajaran itu sendiri merupakan kerangka atau konsep yang dirancang oleh guru atau tenaga pendidik untuk melaksanakan sebuah proses pembelajaran dengan berbagai cara yang dianggap dapat membuat proses belajar mengajar menjadi lebih efektif sehingga dapat mencapai tujuan pembelajaran. Sejalan dengan pernyataan Rusman (2012) yang menyatakan bahwa proses pembelajaran peserta didik itu berasal dari sharing 
3152 Meta Analisis Model Pembelajaran Cooperative Learning Tipe Student Team Achievement Divisions terhadap Hasil Belajar Kognitif SiswaSekolah Dasar - Kezia Febri Kristiani, Gamaliel Septian Airlanda

DOI: https://doi.org/10.31004/basicedu.v5i5.1328

antar siswa, sehingga mereka dapat menambah pengalaman dan pemahaman bersama dalam kelompok belajar itu sendiri.

Dengan model pembelajaran cooperatif learning tipe STAD (Student Team Achievement Divison) ini mampu meningkatkan hasil belajar kognitif siswa karena siswa dapat belajar secara berkelompok dan bertukar pikiran dan pengetahuan tetapi peran guru juga tetap dibutuhkan untuk menyampaikan materi, setelah itu siswa dibagi dalam kelompok. Shofiyyatunnisa et al (2020) berpendapat bahwa model pembelajaran kooperatif tipe STAD adalah model pembelajaran yang dapat menambah kemampuan siswa dalam hal berpikir kritis, kreatif dan kerjasama antar teman. Dari sinilah siswa akan belajar untuk bertanya, menjawab, saling membantu antar anggota kelompok, memberikan pendapat dan hal lainnya yang dapat memunculkan menambah pengetahuan anak. Suratmin (2019) mengemukakan bahwa model pembelajaran STAD (Student Team Achievement Division) merupakan salah satu model belajar dalam pembelajaran kooperatif yang dapat membantu siswa agar lebih mudah memahami pengetahuan yang diterima dari guru. Dari model pembelajaran tipe STAD ini tidak hanya bagaimana siswa belajar dalam tim, tetapi juga mengajarkan guru untuk memberikan penghargaan tim, dengan cara mengambil nilai rata-rata per tim. Sehingga hal tersebut dapat menambah semangat siswa untuk mendapatkan hasil belajar yang maksimal, dengan penelitian ini diharapkan dapat mengetahui pengaruh dari model pembelajaran kooperatif learning tipe STAD terhadap hasil belajar kognitif pada siswa.

\section{METODE PENELITIAN}

Penelitian ini menggunakan desain Meta Analisis, Meta Analisis pada penelitian ini untuk meneliti dengan mengkaji 21 artikel secara kuantitatif atau menganalisis hasil dari penelitian sebelumnya. Penelitian ini dilakukan dengan mencari artikel yang ada di google schoolar dengan kata kunci yaitu 'Cooperative Learning tipe STAD (Student Team Achievement Divisions)" dan "Hasil Belajar Kognitif". Artikel yang dikaji ini memiliki kriteria yaitu: (1) terbit 10 tahun terakhir yaitu dari tahun 2013-2020; (2) artikel yang digunakan berjudul model pembelajaran kooperatif learning tipe STAD (Student Team Achievement Divisions) terhadap hasil belajar kognitif siswa sekolah dasar; (3) artikel yang dibuat oleh mahasiswa ataupun umum; (4) artikel yang digunakan mencakup artikel wilayah Indonesia; (5) variable yang digunakan adalah x yaitu model Pembalajaran Cooperative Learning tipe STAD (Student Team Achievement Divisions) dan y hasil belajar kognitif. Artikel yang memenuhi kriteria ini akan digunakan sebagai data pada penelitian yang menunjukan data sebelum perlakukan (pretest) dan sesudah diberikan perlakuan (post test) dalam bentuk skor presentase rata-rata. Lembar kerja coding menjadi instrumen penelitian sebagai sarana menghimpun data dari artikel berupa nomor kode, judul penelitian, nama peneliti, tahun terbit, dan variabel bebas yang digunakan. Teknik analisis data menggunakan uji prasyarat yaitu uji normalitas, uji paired sample test dan menghitung effect size untuk mengetahui seberapa besar pengaruh model Pembelajaran Cooperative Learning tipe STAD (Student Team Achievement Divisons).

\section{HASIL DAN PEMBAHASAN}

Penelitian ini berisi hasil perhitungan peneliti yang menggunakan metode metaanalisis dalam penelitiannya tentang pembelajaran kooperatif learning tipe STAD (Student Team Achievement Divisions) terhadap hasil belajar kognitif siswa di sekolah dasar. Dalam menganalisis dampak penggunaan model pembelajaran kooperatif learning tipe STAD dalam meningkatkan hasil kognitif siswa sekolah dasar, sampel yang digunakan peneliti dalam penelitiannya berupa 21 artikel ilmiah dengan pokok pembahasan yang sama atau penelitian terdahulu yang dianalisis dan disajikan dalam bentuk data baru. 
3153 Meta Analisis Model Pembelajaran Cooperative Learning Tipe Student Team Achievement Divisions terhadap Hasil Belajar Kognitif SiswaSekolah Dasar - Kezia Febri Kristiani, Gamaliel Septian Airlanda

DOI: https://doi.org/10.31004/basicedu.v5i5.1328

Tabel 1.Hasil Analisis Pengaruh Model Pembelajaran Cooperative Learning Tipe STAD

\begin{tabular}{cccccc}
\hline No & Kode & \multicolumn{5}{l}{ Peningkatan Hasil Belajar } & Pata & $\begin{array}{c}\text { Pre } \\
\text { Test }\end{array}$ & $\begin{array}{c}\text { Post } \\
\text { Test }\end{array}$ & Gain & Gain\% \\
\hline 1. & $\mathrm{X} 1$ & 58,9 & 77,03 & 36,13 & $31,33 \%$ \\
\hline 2. & $\mathrm{X} 2$ & 64,88 & 79,77 & 14,89 & $22,95 \%$ \\
\hline 3. & $\mathrm{X} 3$ & 66,53 & 84,23 & 19,71 & $12,02 \%$ \\
\hline 4. & $\mathrm{X} 4$ & 60,11 & 87,99 & 21,7 & $11,23 \%$ \\
\hline 5. & $\mathrm{X} 5$ & 68 & 72,85 & 4,85 & $7,13 \%$ \\
\hline 6. & $\mathrm{X} 6$ & 65,5 & 85,3 & 19,8 & $30,22 \%$ \\
\hline 7. & $\mathrm{X} 7$ & 70,62 & 86,12 & 15,52 & $21,97 \%$ \\
\hline 8. & $\mathrm{X} 8$ & 63,72 & 74,67 & 15,16 & $24,38 \%$ \\
\hline 9. & $\mathrm{X} 9$ & 71,46 & 78,88 & 26,59 & $8,81 \%$ \\
\hline 10. & $\mathrm{X} 10$ & 50,11 & 77,79 & 18,88 & $31,23 \%$ \\
\hline 11. & $\mathrm{X} 11$ & 54,55 & 75,55 & 21,1 & $28,12 \%$ \\
\hline 12. & $\mathrm{X} 12$ & 73,13 & 81,54 & 9,92 & $15,26 \%$ \\
\hline 13. & $\mathrm{X} 13$ & 61,25 & 82,91 & 15,66 & $24,47 \%$ \\
\hline 14. & $\mathrm{X} 14$ & 60,87 & 70,35 & 7,48 & $11,01 \%$ \\
\hline 15. & $\mathrm{X} 15$ & 40,11 & 60,57 & 20,46 & $23,11 \%$ \\
\hline 16. & $\mathrm{X} 16$ & 56,36 & 79,09 & 22,73 & $25,91 \%$ \\
\hline 17. & $\mathrm{X} 17$ & 68,09 & 80,01 & 11,31 & $18,23 \%$ \\
\hline 18 & $\mathrm{X} 18$ & 50,13 & 81,01 & 28,92 & $42,80 \%$ \\
\hline 19 & $\mathrm{X} 19$ & 67,67 & 86,04 & 16,02 & $23,93 \%$ \\
\hline 20 & $\mathrm{X} 20$ & 48,01 & 57,86 & 18,37 & $27,10 \%$ \\
\hline 21 & $\mathrm{X} 21$ & 55,45 & 72,72 & 13,22 & $21,61 \%$ \\
\hline Rata-Rata & 57,22 & 79,59 & 22,95 & $34,52 \%$ \\
\hline
\end{tabular}

Hasil analisis data dari 21 jurnal yang sudah didapatkan, yaitu pada Tabel 1 terdapat pengaruh dalam hasil belajar kognitif siswa dengan menggunakan model pembelajaran Cooperative Learning tipe STAD (Student Team Achievement Divisions) rata-rata peningkatan dari beberapa artikel yang dikumpulkan yaitu 22,95 mulai dari peningkatan terendah 7,13 dan peningkatan tertinggi sampai 42,80. Kemudian hasil belajar rata-rata sebelum dan rata-rata sesudah dengan model Cooperative Learning tipe STAD (Student Team Achievement Divisons) mengalami peningkatan yang cukup signifikan sebesar 34,52\%.

Berikut uji Paired Samples Test dengan berbantuan SPSS 20.00 for windows. Uji Paired Samples Test dilakukan untuk mengetahui ada tidaknya perbedaan sebelum dan sesudah menggunakan model Cooperatif Learning Tipe STAD untuk meningkatkan hasil belajar siswa sekolah dasar. Berikut ini adalah hasil dari analisis uji Paired Samples Test.

\section{Tabel 2.Paired Samples Statistics}

\begin{tabular}{lrrrr}
\hline Mean & $\mathrm{N}$ & Std. Deviation & Std. Error Mean & \\
\hline 57.1353 & 21 & 11.21643 & & 2.44763 \\
\hline 79.2559 & 21 & 8.35864 & & 1.82400 \\
\hline
\end{tabular}

Berdasarkan Tabel 2 diatas, dapat disimpulkan bahwa jumlah skor dari 21 artikel yang digunakan sebagai sumber data oleh peneliti dalam proses penelitian yang dilakukan menunjukkan bahwa pembelajaran dengan menggunakan model Cooperatif Learning Tipe STAD (Student Team Achievement Divisions) mempunyai pengaruh yang sangat besar untuk meningkatkan hasil belajar kognitif siswa sekolah dasar. Pada nilai rata-rata pretest menggunakan model Cooperatif Learning Tipe STAD menunjukkan angka yaitu sebesar 
3154 Meta Analisis Model Pembelajaran Cooperative Learning Tipe Student Team Achievement Divisions terhadap Hasil Belajar Kognitif SiswaSekolah Dasar - Kezia Febri Kristiani, Gamaliel Septian Airlanda

DOI: https://doi.org/10.31004/basicedu.v5i5.1328

57,1353. Sesudah menggunakan model pembelajaran Cooperatif Learning Tipe STAD nilai posttest mengalami kenaikan yang signifikan yaitu 79,2559. Dari jumlah skor menunjukkan adanya perubahan yang signifikan sehingga membuktikan bahwa dengan menggunakan model Cooperatif Learning Tipe STAD dapat membantu untuk meningkatkan hasil belajar kognitif siswa sekolah dasar.

Tabel 3.Uji Paired Samples Correlations

\begin{tabular}{llll}
\hline & $\mathrm{N}$ & Correlation & Sig. \\
\hline pretest \& posttest & &
\end{tabular}

21

.403

.070

Dari Tabel 3 di atas dapat dilihat bahwa nilai Sig yaitu $0,70>0,05$. Dapat disimpulkan bahwa tidak terdapat hubungan antara variabel pretest dan posttest dikarenakan $>0,05$.

Tabel 4. Uji Paired Samples Test

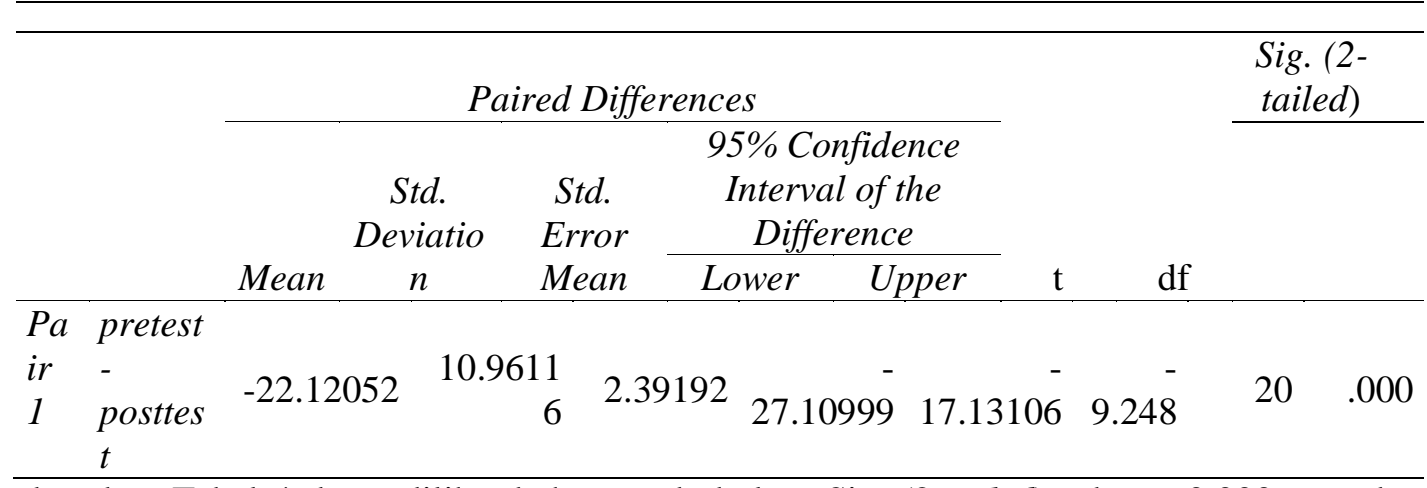

Berdasarkan Tabel 4 dapat dilihat bahwa pada kolom Sig. (2-tailed) sebesar 0,000 yang berarti lebih kecil dari $0,05(0,000<0,05)$ berarti bahwa $\mathrm{H}_{\mathrm{o}}$ ditolak dan $\mathrm{H}_{\mathrm{a}}$ diterima. Selain itu, dapat dilihat $\mathrm{t}_{\text {hitung }}$ sebesar 9.248 dan tabel yang diperoleh sebesar 1,72472. Berdasarkan hasil proses penghitungan yang dilakukan oleh peneliti maka dapat dilihat pada tabel di atas menunjukkan terdapat perbedaan yang signifikan pada peningkatan hasil belajar kognitif siswa sekolah dasar sebelum dan sesudah menggunakan model Cooperatif Learning tipe STAD (Student Team Achievement Divisons).

Besarnya pengaruh dari penggunaan model Cooperatif Learning Tipe STAD (Student Team Achievement Divisions) untuk meningkatkan hasil belajar kognitif siswa sekolah dasar dapat diukur pengaruhnya menggunakan uji Effect Size. Berikut ini adalah interperensi Effect Size berdasarkan Cohen:

Tabel 5.Interpretasi Effect Size

\begin{tabular}{cc}
\hline Batasan & Kategori \\
\hline $0,2-0,5$ & Kecil \\
\hline $0,5-0,8$ & Sedang \\
\hline $\mathrm{d}>0,8$ & Besar \\
\hline
\end{tabular}

Penggunaan Effect Size yang bertujuan untuk membuktikan pengaruh dari model Cooperatif Learning Tipe STAD (Student Team Achievement Divisions) terhadap hasil belajar kognitif siswa sekolah dasar. Hasil hitungan yang dilakukan oleh peneliti maka di dapat hasil yang tertera pada Tabel 3 yaitu skor pada saat pretest memiliki mean sebesar 57.1353 dengan standar deviasi sebesar 11.21643. Kemudian pada saat dilakukan posttest kemudian mean mengalami kenaikan yang signifikan yaitu sebesar 79.25559 dengan standar deviasi sebesar 8.35864. Berikut ini rumus yang digunakan untuk pengujian Effect Size berdasarkan Cohen: 
3155 Meta Analisis Model Pembelajaran Cooperative Learning Tipe Student Team Achievement Divisions terhadap Hasil Belajar Kognitif SiswaSekolah Dasar - Kezia Febri Kristiani, Gamaliel Septian Airlanda

DOI: https://doi.org/10.31004/basicedu.v5i5.1328

$$
d=\frac{M_{\text {posttest }}-M_{\text {pretest }}}{\sqrt{\frac{\left(S D_{\text {pretest }}{ }^{2}+S D_{\text {posttest }}{ }^{2}\right)}{2}}}
$$

Keterangan:

$$
\begin{array}{ll}
d & =\text { Effect } \text { Size } \\
\mathrm{M}_{\text {pretest }} & =\text { mean pretest } \\
\mathrm{M}_{\text {posttest }} & =\text { mean posttest } \\
\mathrm{SD}_{\text {pretest }} & =\text { standar deviasi pretest } \\
\mathrm{SD}_{\text {posttest }} & =\text { standar deviasi posttest }
\end{array}
$$

Hasil hitungan yang dilakukan oleh peneliti menggunakan rumus uji Effect Size diatas, maka diperoleh hasil berupa data yang tertera pada tabel. Berdasarkan data pada Tabel 4 dapat dihitung menggunakan rumus diatas, sebagai berikut perhitungan menggunakan rumus:

$$
\begin{aligned}
& d=\frac{M_{\text {posttest }}-M_{\text {pretest }}}{\sqrt{\frac{\left(S D_{\text {pretest }}{ }^{2}+S D_{\text {posttest }}{ }^{2}\right)}{2}}} \\
& d=\frac{79,25559-57,1353}{\sqrt{\frac{\left(11,21643^{2}+8,35864^{2}\right)}{2}}} \\
& d=\frac{22,12029}{\sqrt{\frac{125,808301945+69,8668626496}{2}}} \\
& d=\frac{22,12029}{\sqrt{\frac{195,675164595}{2}}} \\
& d=\frac{22,12029}{13,9883939248} \\
& d=1,58133164671 \\
& d=1,6
\end{aligned}
$$

Diperoleh hasil hitung effect size yaitu sebesar 1,6 dan melihat pada Tabel 5 tentang interpretasi effect size termasuk dalam kategori besar. Dapat disimpulkan bahwa dengan penerapan model Cooperative Learning Tipe STAD (Student Team Achievement Divisions) memiliki pengaruh yang besar terhadap hasil belajar kognitif siswa sekolah dasar.

Penelitian ini dilakukan untuk mengetahui apakah terdapat perbedaan hasil pembelajaran Cooperative Learning tipe STAD (Student Team Achievement Divisions). Pada penelitian ini, peneliti menggunakan penelitian analisis. Peneliti mendapatkan 21 artikel yang relevan dengan penelitian yang dilakukan. Pada peresentase peningkatan hasil belajar IPA siswa dengan model Problem Based Learning dari skor yang terendah $7,13 \%$ hingga yang tertinggi $42,80 \%$ dengan angka rata-rata $34,52 \%$. Rata-rata nilai hasil belajar siswa sebelum menggunakan model Problem Based Learning adalah 57,22\% kemudian mengalami peningkatan yang signifikan yaitu menjadi $79,59 \%$. Uji prasyarat yang digunakan adalah uji normalitas yang berdistribusi normal. Uji normalitas ini menggunakan data Shapiro-wilk dengan bantuan SPSS 22.00 for windows yang menunjukkan nilai signifikan > 0,05 dengan ini maka dapat dikatakan bahwa data berdistribusi normal. Selanjutnya dilakukan uji Paired Samples Test dengan berbantuan SPSS 22.00 for windows. Uji Paired Samples Test ini dilakukan untuk mengetahui apakah ada perbedaan sebelum dan sesudah menggunakan model pembelajaran Cooperative Learning tipe STAD (Student Team Achievement Divisions) terhadap hasil belajar kognitif siswa sekolah dasar. 
3156 Meta Analisis Model Pembelajaran Cooperative Learning Tipe Student Team Achievement Divisions terhadap Hasil Belajar Kognitif SiswaSekolah Dasar - Kezia Febri Kristiani, Gamaliel Septian Airlanda

DOI: https://doi.org/10.31004/basicedu.v5i5.1328

Model Pembelajaran tipe STAD merupakan pendekatan Cooperative Learning yang menekankan pada aktivitas dan interaksi diantara siswa untuk saling memotivasi dan saling membantu dalam menguasai materi pelajaran guna mencapai prestasi yang maksimal.

Berdasarkan uji Paired Samples Statistics menunjukkan nilai rata-rata pretest menggunakan model pembelajaran tipe STAD (Student Team Achievement Divisions) yaitu sebesar 57.1353. Nilai post test mengalami kenaikan yang signifikan yaitu 79.2559. Dari jumlah skor menunjukkan adanya perubahan yang signifikan sehingga membuktikan bahwa dengan menggunakan model pembelajaran Cooperative Learning tipe STAD dapat membantu meningkatkan hasil belajar kognitif siswa di sekolah dasar. Hasil uji Paired Samples Correlations adalah nilai Sig yaitu 0,70 >0,05. Sehingga dapat disimpulkan bahwa tidak terdapat hubungan dikarenakan nilai signifikan >0,05. Hasil uji Paired Samples Test menunjukan bahwa pada kolom Sig. (2-tailed) sebesar 0,000 yang berarti lebih kecil dari $0,05(0,000<0,05)$ yang berarti bahwa Ho ditolak dan Ha diterima. Selain itu, dapat dilihat thitung sebesar -9.248 dan ttabel yang diperoleh sebesar .1,72472. Dapat disimpulkan bahwa terdapat perbedaan yang signifikan pada peningkatan hasil belajar kognitif siswa dengan menggunakan model pembelajaran Cooperative Learning tipe STAD. Hasil penelitian ini sejalan dengan penelitian yang dilakukan oleh Wina Dwi Puspitasari pada tahun 2018 dengan judul "Implementasi Model Pembelajaran Kooperatif Tipe STAD Student Team Achievement Divisions Dalam Meningkatkan Hasil Belajar IPS Siswa" menunjukkan bahwa hasil uji t posttest menunjukkan $t$ hitung $-4,107$ dan $t$ table 3,163 dengan signifikansi $0,002<0,05$ maka Ho ditolak dan Ha diterima yang artinya ada suatu perbedaan yang signifikan antara hasil belajar yang menggunakan model pembelajaran tipe STAD. Berdasarkan perhitungan effect size diperoleh hasil yaitu sebesar 1,6 menunjukkan pengaruh yang besar jika melihat kembali pada tabel 5 tentang interpretasi effect size. Dapat disimpulkan bahwa dengan menggunakan model pembelajaran Cooperative Learning tipe STAD mampu memberikan pengaruh yang besar terhadap hasil belajar kognitif siswa sekolah dasar. Sejalan dengan pendapat Nindrea (2016) Effect size efek antara 2 kelompok dalam studi meta analisis yang memiliki perbedaan kejadian. Sehingga bisa disimpulkan bahwa dengan menggunakan model pembelajaran model Cooperative Learning tipe STAD (Student Team Achievement Divisions) memiliki pengaruh yang sangat besar terhadap hasil belajar kognitif siswa sekolah dasar.

\section{KESIMPULAN}

Berdasarkan hasil analisis diatas dapat disimpulkan bahwa model pembelajaran Cooperative Learning Tipe STAD (Student Team Achievement Divisions) berpengaruh sangat besar dalam meningkatkan hasil belajar siswa kognitif siswa sekolah dasar dengan rata rata sebesar 22,95 dapat dilihat dari peningkatan terendah dari model pembelajaran Cooperative Learning tipe STAD berdasarkan hasil analisis data dari sejumlah jurnal. Hal ini dapat dilihat bahwa model pembelajaran Cooperative Learning Tipe STAD dapat meningkatkan hasil belajar kognitif di sekolah dasar. Terdapat peningkatan hasil belajar dengan rata-rata sebesar 34,52\% mulai dari peningkatan terendah 7,13\% sampai yang tertinggi 42,80\%. Sementara hasil belajar rata-rata sebelum dan sesudah menggunakan metode pembelajaran tersebut mengalami peningkatan yang signifikan yaitu sebesar 34,52\%. Hasil uji effect size yang diperoleh sebesar 1,6 sehingga bisa dikatakan dengan menggunakan model pembelajaran Cooperative Learning tipe STAD (Student Team Schievement Divisions) berpengaruh sangat besar dalam meningkatkan hasil belajar kognitif siswa sekolah dasar. 
3157 Meta Analisis Model Pembelajaran Cooperative Learning Tipe Student Team Achievement Divisions terhadap Hasil Belajar Kognitif SiswaSekolah Dasar - Kezia Febri Kristiani, Gamaliel Septian Airlanda

DOI: https://doi.org/10.31004/basicedu.v5i5.1328

\section{UCAPAN TERIMA KASIH}

Peneliti sekaligus penulis mengucapkan banyak terimakasih kepada seluruh pihak yang telah membantu dan menjadi penyemangat jalannya penelitian ini. Puji syukur kepada Tuhan Yang Maha Esa untuk setiap kemudahan yang diberikan selama proses penelitian ini berlangsung. Tak lupa ucapan terimakasih untuk dosen pembimbing, keluarga, dan juga teman-teman yang telah memberikan dukungan secara penuh selama penelitian.

\section{DAFTAR PUSTAKA}

Abdullah, N. (2018). Upaya Meningkatkan Hasil Belajar Bahasa Indonesia Aspek Menulis Dengan Penggunaan Model Kooperatif Learning Tipe Stad. Jurnal Pendidikan Tambusai, 2(2), 220. Https://Doi.Org/10.31004/Jpt.V2i2.669

Ayuwanti, I. (2017). Meningkatkan Aktivitas Dan Hasil Belajar Matematika Menggunakan Model Pembelajaran Kooperatif Tipe Group Investigation Di Smk Tuma'ninah Yasin Metro. Sap (Susunan Artikel Pendidikan), 1(2), 105-114. Https://Doi.Org/10.30998/Sap.V1i2.1017

Nasution, M. K. (2017). Penggunaan Metode Pembelajaran Dalam Peningkatan Hasil Belajar Siswa. 11(1), 9-16.

Nindrea, Ricvan Dana. (2016). Pengantar Langkah- Langkah Praktis Studi Meta Analisis. Gosyen Publishing.

Pendidikan, M., Kebudayaan, D. A. N., \& Indonesia, R. (2016). Salinan Peraturan Mentri Pendidikan Dan Kebudayaan Republik Indonesia Nomor 22 Tahun 2006 Tentang Standar Proses Pendidikan Dasar Dan Menengah.

Prawati, S. (2016). Penerapan Metode Pemberian Tugas Untuk Meningkatkan Hasil Belajar Siswa Dalam Pembelajaran Ips Pada Siswa Kelas V Sdn No 1 Pangalasiang. Jurnal Kreatif Tadulako Online, 4(2354$614 x), 1-17$.

Prihatnani, E., \& Supriyadi, D. (2021). Proses Metakognisi Mahasiswa Calon Guru Matematika Dalam Memecahkan Masalah Piramida Hitung. 7(2), 210-226.

Rusman. (2012). Model Pembelajaran Kooperatif Tipe Student Teams Achievement Division Terhadap Kemampuan Komunikasi Matematis. 13-46.

Shofiyyatunnisa, A., Pujiastuti, H., Matematika, P., Tirtayasa, S. A., \& Pendahuluan, A. (2020). Penerapan Model Student Team Achievement Division ( Stad ) Ditinjau Dari Kemampuan. Pedagogy: Jurnal Pendidikan Matematika, 5(1), 20-30.

Suratmin, S. (2019). Penerapan Model Pembelajaran Student Teams Achievement Division (Stad) Untuk Meningkatkan Prestasi Belajar Bahasa Inggris. Jurnal Dikdas Bantara, 3(1), 333-340. Https://Doi.Org/10.32585/Jdb.V3i1.582

Wahyuningsih, S. S., Darmayanti, T., Bintarti, A., \& Terbuka, U. (2019). Meta Analisis Tutorial Online. Jurnal Pendidikan Terbuka Dan Jarak Jauh, Vol.20(No.1 Maret), 32-38.

Wayuningati, N. R. (2017). Penerapan Problem Based Learning Dan Media Flipcart. Ilmu Pendidikan, 2(2), 184-188 